could be given to folk museums by systematic circularization of those in close touch with the countryside.

For the first time in the history of the Association and as an experiment a session was given to sectional meetings. In that devoted to archæology, ethnography and folk-life, Dr. D. B. Harden was chairman, and Mr. R. J. C. Atkinson gave a paper on "A National Index of Archæological Collections". Mr. Atkinson sought the co-operation of museums in the compilation of illustrated indexes of British archæological objects: (1) Inventaria Archæologica of associated groups chiefly of the 2nd millennium B.c.an international project of which some Belgian and German cards are published ; (2) British Association card index of bronze implements, formerly in the British Museum, now at Oxford, in abeyance since 1939 ; (3) Corpus of Bronze Age pottery, being organized by the Council for British Archæology; and (4) School of Scottish Studies, Edinburgh, neolithic and bronze age indexes. Mr. F. G. G. Carr (National Maritime Museum) and Miss Elspeth M. Gallie (Old Glasgow Museum) then dealt with the difficult problem of the purposeful display of personalia and historical relics. Both speakers stressed the need for proving the authenticity of personalia and historical relics and, if possible, for exhibiting them as part of a well-defined and general pattern. An endeavour must be made to re-create the person to the visitor.

In the section dealing with art and applied art, the president took the chair, and the first discussion was opened by Prof. A. F. Blunt, of the Courtauld Institute of Art, whose subject was "The Teaching of Art History, and the Museum Profession". He described the training in the history of European art provided at the Courtauld Institute. The Institute could not, he stressed, give instruction in the administrative and technical aspects of museum work-this came only with experience and specialized training; but it did provide education of a high standard of great value to entrants to the museum profession.

The other speaker was Miss Helen Gluck, who discussed "The Dilemma of the Painter and Conservator in the Synthetic Age". She showed how, since the commercial introduction of packaged paints, the quality of artist's materials had deteriorated. The situation had become worse since the introduction by the colourmen of synthetic materials. If the paintings of to-day were to survive, the most thorough investigation was required, and a centre, which would make it its business to see that standards were maintained, should be established. Miss Gluck's paper was the subject of lively discussion and the meeting agreed to recommend to the Ministry of Education, as the body responsible for most of the schools of art, that this matter be givon serious attention.

The third section, under the chairmanship of Dr. W. E. Swinton, discussed two difficult but important fields for museum treatment. Mr. D. Chilton (Science Museum) defined the essentials of display for meteorology, which is becoming increasingly of public interest, recommending the exhibition of the standard instruments, in use, if possible, and a selection of cloud photographs. Dr. John Burton (medical director of the Central Council for Health Education) stressed the ways in which the local museum could play its part in the hygiene campaign and discussed the kinds of travelling exhibitions which were and could be prepared, and the part that the local medical officer of health could, and probably would, play in co-operation with the museum.

Dr. F. J. North, chairman of the Education Committee, opened a discussion on training problems in the museum profession. After referring to the difficulties of the task and its consequent challenge, he said that it should be possible to induce at least one university to establish a department of museology, or better still, to create conditions in which the Association could have its own training institution. Subsequent speakers stressed that such a training should be in the nature of a postgraduate diploma course. The training needs of museum curators fall into two categories. First, instruction in some museum subject generally received in a university or equivalent institution, and secondly, the application of that knowledge to the needs of a museum. As matters are at present, training in the latter part can only be given in museums and several traineeassistant schemes are in operation. Dr. North naturally summarized the diploma scheme of the Museums Association for curators and the more recently instituted technical certificate. Opportunity was taken at the end of the discussion to express the gratitude of the Association for his great services during his eight years chairmanship of the Education Committee and for his pioneer work with regard to the establishment of the diploma and technical certificate.

The hospitality of Edinburgh was extended to members by receptions at the Assembly Rooms, the Royal Scottish Museum and the Scottish United Services Museum, and the Association was honoured by the presence of the Lord Provost and other distinguished citizens at its annual dinner. Tours to Loch Lomond and the Loch Sloy scheme, Haddington. and East Lothian and the Border Abbeys closed a stimulating week.

At the annual meeting of the Association, Sir Leigh Ashton was re-elected president, and Mr. E. C. Chubb, director of the Durban Museum and Art Gallery during 1910-51, was elected an honorary fellow. It was decided to hold the next conference at Birmingham during July 4-8, 1955.

\section{THE UPPER ATMOSPHERE}

A $S$ part of its summer meeting in the University A of Edinburgh during July 15-17, the Royal Meteorological Society held a symposium on "The Upper Atmosphere". Dr. O. G. Sutton, president of the Society and director of the Meteorological Office, presided.

The first speaker at the symposium was Sir Edward Appleton, principal of the University, who began by emphasizing the remarkable complexity of the structure of the upper atmosphere and proceeded to give a survey of the present state of our knowledge of the subject, indicating the regions that are the scats of the various phenomena which were to be discussed by subsequent speakers in the symposium. He likened the upper atmosphere to a vast laboratory in which the sun daily actuates a series of experiments at low pressures, in conditions and on a scale which we cannot hope to reproduce experimentally. Solar ultra-violet radiation creates, at different levels, the ozonosphere and the ionosphere by dissociating molecules and by ionizing both atoms and molecules. Further, the gravitational attraction of the sun and moon causes marked atmospheric tides at high 
levels, and the influence of the earth's magnetic field comes into action as soon as any charged atmospheric particle begins to move. Meteors, sporadic and in showers, produce streaks of ionization which can be observed by eye if clouds are absent and alwayseven in Manchester-by radio. It may be that fine meteoric dust forms a permanent part of the ionosphere.

Sir Fdward then discussed some ionospheric problems which he and his research assistants in Edinburgh, Mrs. Pritchard and A. J. Lyon, have recently examined. "If the nature of your occupation prevents you from doing any experiments, it need not prevent you from thinking-thinking about other people's measurements." In the field of geophysics, many people are engaged in making measurements, but he sometimes wondered whether enough people are thinking about what these measurements mean, when they are compared with one another. He and his assistants have been examining measurements of ionization densities in the layers of the ionosphere from a world point of view by using the observations of ionospheric stations operating in different parts of the world.

Examining first the world morphology of the $F 2$ layer, they investigated the variation of $f F^{2}$ at noon at the equinoxes with both geographical and geomagnetic latitude and have found the closer fit with the latter. The curve shows a trough in the region of the equator, where $f F 2$ is a minimum. When curves are drawn for other times of the day, it is found that in the late evening hours the trough becomes a crest. No such effect appears in similar curves drawn for the $E$ and $F 1$ layers. This difference between the $F 2$ layer and the lower $E$ and $F 1$ layers is not thought to indicate that the $F 2$ layer is caused by electrified corpuscles. They think that ultra-violet radiation, certainly the cause of the $E$ and $F 1$ layers, is also responsible for the $F 2$ layer and that the effect is due to geomagnetic distortion. The movements associated with the diurnal oscillation, tidal or thermal in origin, which these observations disclose, would be subject to strong control by the geomagnetic field at the low densities obtaining at the $F 2$ lovel. But, though theories have been proposed by Martyn, Maeda and Weiss, there is as yet no satisfactory theoretical explanation. The investigation of the $F 2$ layer by Sir Edward and his co-workers has further revealed that, during an ionospheric storm, the value of noon $f F^{\mathrm{T}} 2$ is reduced. in high latitudes and increased at the equator.

While their examination of the world morphology of the $E$ and $F 1$ layers has shown no strikingly abnormal effects, even here there are small departures from simple theory. It was well worth while investigating such discrepancies, for there is always the possibility that the investigation may yield a method of measuring the magnitude of the factor which itself causes the discrepancy. In illustration, Sir Edward then considered some features of the $E$ layer, and from the continuity equation showed that, in an ionized medium :

$$
N=\sqrt{\frac{q_{0} \cos \chi}{\alpha}},
$$

where $N$ is the ion (or electron) concentration, $\chi$ the zenith distance of the sun and $\alpha$ the coefficient of recombination. If $q_{0}$ and $\alpha$ are constant, then $N$ is uniquely determined by $\cos \chi$. A curve showing the annual variation of $N_{E}$ for constant $\chi$ may be drawn using experimental data, since $\chi$ is the same at noon in winter and in the early morning or late evening in summer. 'They have found, in fact, that $N_{E}$ for constant $\chi$ has a minimum in June, so that either $q_{0}$ or $\alpha$, or both, varies; conditions are not the same in summer and winter at the same height.

Finally, Sir Edward discussed the methods they are using in their attempt to determine accurate values of the recombination coefficient at low pressures at all times of the day throughout the year and showed how the coefficient may be determined from observation of the time-lag between the maximum of the ionizing process (at noon) and the ionization maximum; values of the order of $10^{-9}$ and $10^{-8}$ have been obtained. 'They have taken the opportunity, afforded by the recent eclipse, of making such measurements at a minimum of solar influence; $\mathrm{Mr}$. Lyon has successfully made radio observations on the ionosphere at Slough, and they are at present engaged on working out the results.

By studying the reflexion of radio waves from the trail of ionized air produced by a meteor, the atmosphere at heights between about 85 and $105 \mathrm{~km}$. may be sampled, simply and at low cost, several hundred times per hour throughout the day. Dr. Ian C. Browne summarized the results obtained by many workers using this method at Jodrell Bank, University of Manchester, since 1946. Measurements of air density and of scale height (about $3 \times 10^{-9} \mathrm{gm}$. per c.c. and $6.5 \mathrm{~km}$. respectively at $95 \mathrm{~km}$.) may be obtained from observations of the intensities and heights of appearance of meteor echoes, and the atmospheric diffusion coefficient may be calculated from the time of duration of the echoes. In addition, movements of meteor trails of the order of one metre may be detected by using a special technique, so permitting the measurement of wind speed at the height of the trail, for 'meteor winds', in contrast to those obtained by ionospheric methods, are true mass movements of the air. Superimposed on a prevailing wind of about $10 \mathrm{~m}$. $/$ sec., there is a semidiurnal component which may have an amplitude of $30 \mathrm{~m} . / \mathrm{sec}$.; the phase and amplitude of this semidiurnal component show seasonal changes. The winds increase with height, the value of the shear being about $2 \times 10^{-3}$ per sec., that is, roughly the same as in the troposphere; but there is no change in wind direction with height and no detectable vertical component. Dr. O. G. Sutton asked if Dr. Browne eould suggest a mechanism which would account for the maintenance at such great heights of such a regular shear. Dr. Browne was of the opinion that the explanation lies in the temperature distribution at these levels. Dr. T. W. Wormell doubted if the motion of an ionized meteor trail is identical in magnitude and direction with the general air-motion at the same level; he questioned if we could neglect completely the effect of magnetic forces on the moving ions and electrons.

Dr. H. P. Palmor summarized the work at Jodrell Bank on the fluctuations of the power received from the intense sources of radio emission in Cassiopæia and Cygnus. The facts that the fluctuations occur mainly during the night and that the degree of fluctuation varies from night to night, showing a close correlation with the occurrence of 'spread $F$ ' ionospheric echoes, indicate that the cause is a terrestrial agency, which is thought to be a diffracting screen of irregularities above the maximum of ionization in the $F$ region. Small time-differences, which are detectable when records from receivers 2-3 km. apart are compared, are interpreted as 
evidence of drift motions of the diffracting screen. Drift speeds of $50-300 \mathrm{~m} . / \mathrm{sec}$. in an east-west direction have recently been determined from approximately vertical observations from three stations. During the months December-April, when these stars transit near midnight, the drift is found to be easterly until $01 \mathrm{hr}$., U.T., then to reverse sharply and to remain westerly thereafter. When the stars are observed at lower culminations, the line of sight traverses the $F$ region in the auroral zone, and fluctuations are then observed at all times, even on magnetically quiet days. Drifts now observed are of greater magnitude and more variable direction, predominantly towards the east during the period 19-21 hr., and towards the north-east or north-west during 2l-06 hr.; but it may be that the apparent north-south components arise from vertical motions.

During an investigation into methods of representing the wind field at the $100-\mathrm{mb}$. pressure-level, it was found that winds observed at this level from British upper-air stations show diurnal and semidiurnal variations. D. H. Johnson, of the Napier Shaw Laboratory, Meteorological Office, Dunstable, gave an account of an analysis he has made of these solar tides in the lower stratosphere. He pointed out that observations at the $100-\mathrm{mb}$. level are particularly suitable for this study since the lower stratosphere is relatively free from effects that might mask the tides; synoptic variations of wind, for example, are small. Using observations made by radar and radio direction-finding techniques, he computed the deviations of the annual mean south- and west-wind components at three-hourly intervals from the respective overall annual mean wind components and found expressions for the annual mean oseillation of each component by harmonic analysis. He found that the stratospheric oscillation is approximately in phase with the surface wind oscillation derived theoretically by Bartels from Simpson's expression for the semidiurnal variation of surfece pressure, a result in accordance with tidal theory. The amplitudes of the south and west wind-component oscillations at the $100-\mathrm{mb}$. level are 0.67 and 0.51 knots, respectively. The corresponding values derived by Bartels for the surface wind-component oscillations are 0.87 and 0.85 knots, respectively [see also p. 363].

D. H. McIntosh, superintendent of Eskdalemuir Observatory, discussed the possibility of determining winds at ionospheric levels from geomagnetic observations. $\mathrm{He}$ outlined the development of theoretical work on the problem of the interpretation of geomagnetic observations since Balfour Stewart suggested in 1882 that the upper atmosphere is highly conducting and that its daily horizontal tidal movement across the vertical component of the earth's field induces currents, the magnetic field of which is observed at the ground as the magnetic daily variation. Schuster, and later Chapman, have developed the theory of the magnetic sular daily variation and of the corresponding lunar effect. While many problems remain unresolved, the theory in its fundamentals has received striking confirmation in several ways, initially by the experimental discovery of the ionosphere and most recently by the discovery by a rocket ascent of a discontinuity of the geomagnetic field at about $100 \mathrm{~km}$., revealing the presence there of a current sheet. So, the dynamo theory of the daily magnetic variation implies that any mass movement of air at ionospheric levels must register in the magnetic records. Wulf has recently examined the problem of determining ionospheric winds in this way, but success has been limited. Vestine, on rather debatable assumptions, has derived wind systems compatible with the annual variation of magnetic disturbance and with the features shown by a particular magnetic storm. Mr. McIntosh was confident that, with the prospect of obtaining direct measurements of ionospheric winds by means of the newly developed radar-sonde, important progress with this problem is likely in the near future.

A paper by Dr. A. H. Jarrett, of the University of St. Andrews, on the possibilities of multilayer coatings for auroral research was read by J. Paton, University of Edinburgh, Dr. Jarrett having been detained after his eclipse observations in Sweden longer than anticipated. Examination of the spectrum of auroræ provides a method of estimating temperature at auroral levels; but, because of the low dispersion of auroral spectrographs and of the long exposures necessary with an extended source like the aurora, measurements are difficult and results uncertain. The use of multilayer coatings in place of the usual silver films in the interferometer considerably reduces absorption and so the times of exposure. With exposures as short as twenty minutes, Dr. Jarrett has recorded Fabry-Perot fringes from auroræ using the $5577 \mathrm{~A}$. line, by placing the interferometer in front of the f/2 Summar 5-cm. focal length camera lens. This preliminary investigation indicates the great possibilities of the use of multilayer coatings in auroral spectroscopy. The United States National Committee for the International Geophysical Year has generously proposed to lend to the British Committee the latest type of auroral spectrograph, working at $f / 0.8$ with a dispersion of $25 \mathrm{~A} . / \mathrm{mm}$. This instrument will be installed at St. Andrews Observatory and will make possible the first British measurements of temperature from auroral spectra. Dr. Jarrett hopes to equip the instrument with $a_{0}$ photoelectric scanning arrangement for direct recording.

Brilliant displays of the rare noctilucent clouds have recently been seen from central Scotland, and their height, position and speed have been determined from parallactic photographs. Mr. Paton discussed the importance of observations of these clouds in providing information concerning the physical state of the upper atmosphere at the height of about $80 \mathrm{~km}$. at which they invariably occur. Besides yielding direct measurements of wind, they indicate the existence of a temperature minimum at $80 \mathrm{~km}$. Wind speeds of the order of $50 \mathrm{~m}$./sec. have been measured; Störmer has recorded speeds of more than $100 \mathrm{~m}$. $/ \mathrm{sec}$., and Jesse of about $300 \mathrm{~m}$. $/ \mathrm{sec}$. On every occasion when the clouds have been observed from Scotland, this movement has been from the east-north-east. But, since they are made visible by the sunlight scattered by the material of which they are composed, they are observed only on nights when the sun remains close below the horizon-that is, during the summer months in middle latitudes. Presumably they may be present at other times and in other latitudes, but they will not remain sunlit long enough to be observed. Their nature is still in doubt, though their tendency to appear at times of comet and meteor occurrences strongly supports the belief that they consist of meteoric dust. E. G. Bowen has recently pointed out that they appear either on or very near the dates of the daylight meteor streams discovered at Jodrell Bank, but Scottish observations show no such tendency. On one occasion, a portion of the clouds was observed to 
change colour from vivid blue to white, suggesting growth of the cloud particles by condensation. When opportunity offers, the new spectrograph at St. Andrews will be employed to investigate such changes in the spectrum. Finally, slides were shown illustrating a remarkably sudden change from their characteristically stable structure to quite chaotic shapes that occurred in the early morning of July 25, 1950. Noctilucent clouds have been observed on twenty-two nights since 1939 ; but this was the only occasion when turbulence was seen. It may be significant that it was also the only occasion when aurora occurred simultaneously with the noctilucent clouds.

\section{OBITUARIES}

\section{Prof. J. T. Hewitt, O.B.E., F.R.S.}

Prof. J. T. Hewits, while crossing the road near his home at Hurst, Berkshire, on July 9, was knocked down and killed by a motor-car. Although he was eighty-five years of age, he was still active, and his death came as a shock to all who knew him. He was born at Windsor in 1868. After an unconventional schooling, he went to the Hartley Institute (now the University of Southampton) and at sixteen was a student at the Normal School of Science (later the Royal College of Science). At eighteen he was a scholar of St. John's College, Cambridge. He took the Normal School associateship in 1887, and three years later had a first in both parts of the Natural Sciences Tripos and a first in the London Honours B.Sc. Before 1893 was out, he had worked in Heidelberg and in Berlin and had acquired the Ph.D. (Heidelberg) and the D.Sc. (London). $\mathrm{He}$ was appointed professor at the People's Palace Technical Schools at Easter 1894, at the age of twenty-five. In the next twenty years, during which the Schools had emerged as a school of the University of London under the title of East London College (now Queen Mary College), he had as students or research students many men who later rose to important academic, governmental or industrial posts. To make a selection is always invidious, but the following names might be mentioned to show the range of interests involved : H. A. Phillips, A. E. Pitt, T. S. Moore, A. E. Dunstan, J. J. Fox, J. Kenner, G. M. Bennett, J. C. Drummond, A. D. Mitchell, T. F. Winmill and W. G. Hiscock.

Hewitt, F. G. Pope and Clarence Smith shared the lecturing at East London; Hewitt gave the intermediate inorganic lectures, which were first class and very well illustrated by experiments, and all the general and honours lectures on inorganic and on physical chemistry. He also attempted to teach his students some mathematics. What was so attractive about Hewitt's lectures was his unconcealed interest in any and every branch of chemistry : in dealing with sodium thiosulphate he could not keep out Bernthsen's methylene blue synthesis, nor Willgerodt and Mascarelli when he was talking about iodine. To him, metallurgical processes, the phase rule, and the determination of accurate atomic weights were all intellectually diverting.

When Hewitt was elected into the Royal Society in 1910, he had an international reputation as an authority on the relation between colour and constitution. He had original views on fluorescence, on the connexion between depth of colour and degree of conjugation, on the constitution of phenthiazine and safranine dyes and on other subjects. Any student in his department who showed ability and enthusiasm was encouraged by Hewitt to get through the routine analytical course as quickly as possible and start some research.

Hewitt wrote an excellent practical book, "Organic Chemical Manipulations", which was unfortunately allowed to get out of print. He invented a process for the quick maturing of whisky and was consulted by the French wine trade. He played an important part in the famous aspirin law case which was lost by the Bayer group.

During the First World War, Hewitt first worked out processes for manufacturing acetic anhydride and for converting benzene-xylene mixtures into toluene. In 1915 he was commissioned as major and went to the Dardanelles, where he was concerned with such diverse matters as water analysis and cylinders of chlorine. Early in 1916 he returned to England and was seconded to the Department of Explosives Supply. He controlled a small factory at Chiswick, with Clarence Smith as a colleague. They dealt first with explosives and later with materials for chemical warfare. Hewitt was a great admirer of his 'chief', Lord Moulton.

Hewitt resigned from his chair at the end of the First World War and in 1919 joined with T. D. Morson, C. S. Roy, Clarence Smith, J. L. Baker and Miss Hewitt (his much beloved sister) to manufacture fine chemicals (quinine ethyl carbonate, quinoline, methylquinolines, benzthiazole, phenylhydrazine, phenylmethylpyrazolone, etc.). 'This concern gradually decayed for one reason or another, and the Hewitts left it during 1940. Miss Hewitt died in 1943 and thereafter Hewitt lived alone in his cottage at Hurst. He often went to London, to the Chemical Society and to meetings of the University Board of Studies, of which he was an original member (1901). $\mathrm{He}$ was one of the first Fellows of Queen Mary College.

Hewitt was a good chemist, a very human personality and (there is no other word) a gentleman. $\mathrm{He}$ enjoyed his life and his memories. It was always a pleasure to see him enter a room full of people he knew : that characteristic, half-courtly salutationthe irresistible charm of a man who lived and worked with zest.

E. E. Turner

\section{Prof. H. Frankfort}

HenRI Frankfort's most outstanding achievement was to have appreciated and by practical example to have taught others to appreciate the value of archrological evidence as a source of human history. His first work-the two volumes of "Studies in the Early Pottery of the Near East"-was not only an original and pioneer comparison of the then available archæological material from predynastic Egypt, prehistoric Mesopotamia and pre-Hellenic Greece, which despite the unpredictable results of many subsequent excavations still provides the accepted guiding lines for the interpretation of Egyptian prehistory. But his "Studies" also eloquently demonstrated how a detailed objective analysis of ceramic techniques, decorative motives and art styles might disclose a history of very much the same sort as that extracted by philologists from orthodox written sources. Frankfort had been trained in the rigorously literary disciplines of the Classica and Egyptology as taught in Holland during 